\title{
DIABLO Y CH'AMAKANI: ANTROPOFAGIA SIMBÓLICA Y MALEFICIO EN EL ALTIPLANO AYMARA DE BOLIVIA
}

\author{
THE DEVIL AND THE CH'AMAKANI: CURSE AND SYMBOLIC \\ ANTHROPOPHAGY ON THE AYMARA PLATEAU IN BOLIVIA
}

\author{
Gerardo Fernández Juárez.
}

\begin{abstract}
El proceso de diabolización al que fueron sometidas las prácticas rituales indígenas durante el proceso colonial también afectaron al Altiplano aymara de Bolivia. Podemos constatar la continuidad de un género ritual que incluye procedimientos de antropofagia simbólica en los que la figura del demonio aparece como un personaje auxiliar convocado por el especialista ritual de máximo prestigio, el ch'amakani, en las comunidades aymaras ribereñas del lago Titicaca. El artículo muestra un ejemplo etnográfico de un caso de maleficio ritual que afecta a los modelos médicos y enfermedades prevalentes en el Altiplano, mostrando la figura del demonio un ajuste coherente con el resto de seres tutelares que auxilian la labor ceremonial del ch'amakani.
\end{abstract}

Palabras claves: aymaras, Bolivia, ch'amakani, diablo, maleficio.

The process of demonization to which indigenous ritual practices were subject during the period of colonial domination also affected the Aymara Plateau in Bolivia. We can observe the continuity of ritual practices which involve symbolic anthropophagic procedures where the devil appears as a secondary participant summoned by the most prestigious ritual specialist, the Ch'amakani, among the Aymara communities near Lake Titicaca, Bolivia. This article discusses an ethnographic example of ritual performances affecting the medical models and diseases prevailing on the Plateau, with the devil playing a role coherent with that of other tutelary beings taking part in the ceremonial practices celebrated by the Ch'amakani.

Key words: Aymaras, Bolivia, ch'amakani, devil, curse.

\section{Los Relatos Coloniales}

El problema de la percepción del mal en el mundo aymara presenta peculiaridades propias que distan mucho de constituir un marco ortodoxo desde la perspectiva del catolicismo. Los sinsabores vividos por el padre Monast en el Altiplano de Carangas, allá a finales de los sesenta y setenta del pasado siglo tratando de certificar el carácter veraz del credo católico entre sus fieles aymaras, así lo testimonia (Monast 1972). Si el credo católico dista mucho de ser adoptado en sus formas fundamentales por los pobladores aymaras, igual sucede con la persona del "adversario" por antonomasia: el diablo.

En las crónicas de Indias, el diablo aparece forjado por el imaginario español asociado a las prácticas rituales y formas de culto indígenas en un proceso de diabolización que se concreta en todo el ámbito colonial (Cervantes 1996; Fernández Juárez 2012; Sánchez 2007). Es así que el diablo aparece bajo la forma de cabrón encabezando las juntas o reuniones de los brujos y brujas que en el dominio europeo configuran un motivo de larga tradición recurrente a lo largo de su historia, como es el aquelarre, cuyos componentes integradores (canibalismo, infanticidio, transformismo animal, procacidad sexual, maleficios, banquetes nefandos, adoración al diablo..., etc.) han servido sistemáticamente para deslegitimar al otro (Cohn 1997 [1976]), adaptando sus manifestaciones sensibles de forma excepcional al ámbito americano (Cañizares-Esguerra 2008; Federici 2010).

Respecto de los Andes, tenemos algunos ejemplos descriptivos de estas juntas diabólicas que más nos descubren las obsesiones de clérigos y cronistas que los acontecimientos que pretenden describir, como sucede en los relatos europeos de índole similar. Llama la atención el impacto que en tierras americanas pudo tener el caso de la persecución de las brujas de las localidades navarras de Zugarramurdi y Urdax, que dio lugar al auto de fe celebrado en Logroño en noviembre de $1610^{1}$, como refleja el caso que describe el jesuita Luis Facultad de Humanidades de Toledo, Universidad de Castilla-La Mancha, Plaza de Padilla, 4; 45071, Toledo, España.
Gerardo.FJuarez@uclm.es 
Teruel (1617). La relación del jesuita procede de una visita de idolatrías que sitúa en un pueblo de la costa peruana a $120 \mathrm{~km}$ de Lima:

Los brujos de la Barranca tenían sus juntas como las del aquelarre de tierra de Burgos en el pueblo de Cegarramurde [leer Zugarramurdi] porque en un cerrillo ${ }^{2}$ que cae sobre el mar, i tiene en lo alto una buena plaçuela, se juntavan todos ellos i allí se les mostraba el Demonio en figura de león, perro, cabrón i en otras, i juntos los brujos los reprendía de que rezavan $\mathrm{i}$ ablavan en español i de que eran amigos de los españoles sus enemigos ${ }^{3}$. El que quería vengarse de alguno, allí le pedía le ayudase i el Demonio les mandavan traer la sangre de tal que ellos le sacavan chupando el sieso ${ }^{4}$ i la llevavan al Demonio que la convertía en carne aparente i allí cozida o asada se la dava a comer al que se quería vengar i con aquello solo sin frío ni calentura se consumía i moría el otro en el tiempo que el brujo quería. Acabada la junta el Demonio les mandava se mezclasen carnalmente en su presencia y lo azían ora cayesen onbres con onbres ora mugeres con mugeres, padre con ija o ermano con ermana; por fin de todo el Demonio alçava la cola y todos le besavan ${ }^{5}$. Confesó uno destos que no siendo brujo se untó i se allavaen las juntas i que era de tan infernal sabor la sangre que chupada convertía el Demonio en aparente carne que les azia trocar asta echar del pecho i entrañas vivas sus propia sangre i los indios comprobaron esto con que vían a estos brujos y brujas estar seis i diez oras arrojando flujo de sangre del asco i orror que les causava la del que moría ${ }^{6}$. (Duviols 1977:33).

Similares motivos a los del texto de Luis de Teruel encontramos en el célebre relato antiidolátrico de Arriaga (1968 [1621]:208), así como en algunos de los informes de carácter edificante que se envían al general de los jesuitas en Roma con periodicidad anual, conocidos como Cartas Annuas y en los que, a pesar de su carácter edificante, podemos observas vestigios de cierta etnografía religiosa y expresiones coherentes con la época de un diabolismo militante por lo que se refiere a las prácticas rituales indígenas?

\section{La Etnografía Contemporánea}

Los brujos y brujas chupadores de sangre de los niños y niñas, "por el sieso y la natura", a la manera que describen los relatos de la inquisición peninsular en los expedientes por brujería, no encontraron acomodo real en el imaginario de los pobladores andinos y no presentan reflejo contemporáneo alguno en la etnografía. Sin embargo, la figura de los "come hombres" sí permanece anclada en la tradición andina y aymara bajo dos formas precisas, una de ellas el temible kharisiri, lik'ichiri, khariri, que anhela la grasa y la sangre humanas para la elaboración de productos varios implicando, según la creencia, la muerte del afectado, quien no suele descubrir a tiempo la colecta de grasa de que ha sido objeto ${ }^{8}$.

La otra variable sobre el "come hombres" que ha permanecido en la etnografía andina, y que coincide con algunas descripciones coloniales, a pesar de la contaminación expresa que su figura ha sufrido respecto de las aportaciones del catolicismo, es la de aquellos que aparecen en los textos coloniales como "hechiceros y ministros del diablo", que no eran sino especialistas en rituales con una presencia recurrente y un prestigio notable en la vida cotidiana de las comunidades andinas (Fernández Juárez 2012) ${ }^{9}$.

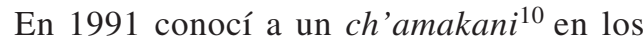
alrededores de la localidad lacustre de Achacachi, capital provincial de Omasuyos en el departamento de La Paz, que era un consumado especialista en la voraz ingesta ritual de personas. Bajo un aspecto afable, inocente y aparentemente inocuo ocultaba un poder sorprendente que solo pude conocer al final por una coincidencia insospechada. Una de las últimas noches que pasé en el Altiplano, por aquel entonces, llegaron a su casa dos jóvenes familiares suyos residentes habituales en los Yungas ${ }^{11}$. El problema que los jóvenes le plantearon parecía serio; toda la familia padecía una mala suerte persistente y sueños extraños que se manifestaban una y otra vez $^{12}$. Emilio, que así se llamaba uno de los jóvenes, soñaba que caía en una sima, chapoteaba en el agua y no podía volver a subir, encerrado en un barranco. Su madre se encontraba muy afligida; querían que el "maestro" les llamase el "ánimo"13 a todos los miembros de la familia, cosa que hizo valiéndose de las ropas que habían traído ambos jóvenes, tanto de la madre como del resto de hermanos menores ${ }^{14}$.

Sin embargo, ellos atribuían su mala suerte al influjo de una familia vecina a quienes consideraban 
responsables de la muerte de su padre y con quienes les unían lazos de parentesco ritual, por cuanto uno de los miembros de la familia y principal sospechoso era padrino de bautismo de una de las hijas de Emilio ${ }^{15}$; al parecer, existían igualmente reclamaciones territoriales por un antiguo litigio de tierras entre ambas familias. Por si fuera poco, estos vecinos son adinerados y Emilio sospecha que también, por dicha causa, cocaineros ${ }^{16}$. Tras la ch'amaka pertinente, y una vez interrogadas las entidades anímicas de los implicados que fueron sometidas a un duro correctivo ${ }^{17}$ por parte del especialista y ante el requerimiento de los clientes que solicitaban un castigo superior, el demonio fue convocado por las aphallas ${ }^{18}$ del "maestro".

En plena oscuridad y después de un golpe sonoro y un silbo penetrante, que acreditaba la llegada del demonio, su presencia entre nosotros se materializó por medio de su voz gruesa:

- JAJAJAJAAJ Buenasssss nochessss ${ }^{19}$.

- Capitán ${ }^{20}$. Nosotros le hemos esperado.

Capitán a usted queremos entregar a este Carmelo Mamani, Julia Mamani y Moisés Mamani.... A nosotros nos quiere meter en calavera $^{21}$, a nosotros nos quieren comer $^{22}$. A Eduardo, a Emilio, a sus hermanos, y a su madre, ;todas las conciencias han burlado! Con eso queremos indicar Capitán, que te conformes con esto; nosotros alterados, a nosotros nos quiere vencer; nosotros no podemos hacer vencer, por eso hemos llamado Capitán. Nosotros entregamos a tu poder; puedes comer; ¡tú sabrás qué hacer! ${ }^{23}$ Estos un poquito capitalistas son estos que manejan cocaína.

- Mañudos, caprichosos. GRRRR...... ROARRR... GRRRRRRR... ${ }^{24}$.

- Bien Capitán. Esa persona se llama Carmelo Mamani, después el otro se llama Julia Mamani ${ }^{25}$, el otro también se llama Moisés.... Después...¿qué se llama? .... Nicolás, Juana, Elena ${ }^{26}$.

- AHHHH GRRR ROOARRR... RRRRRRRR. Voy a comerrrrrr, "asentaron"27.

- ¡Complemento!, Come nomás, come nomás, come nomás; cómelo, cómelo, cómelo Capitán; estamos aquí, nosotros estamos esperando. Cómelo, cómelo, cómelo nomás ${ }^{28}$. Cómelo nomás, cómelo nomás, cómelo nomás, manq'ata, "asentaron", manq'ata $^{29}$. Capitán, por mañudo malcriado Capitán, demonio ¡de una vez! Cómelo hasta el final ${ }^{30}$, cómelo esa persona que son malcriados, cómelo, cómelo de una vez "asentaron", totalmente "asentaron" nos quieren aplastar como un pan....Capitán, cómelo, cómelo, cómelo, cómelo, seguí nomás ${ }^{31}$.

- HAAAAA .........HAAAAAAA.... HAAAAA ....... GUMMMMM...... NGUMMMM...

NGUMM... ${ }^{32}$ Hasta el final no más esss ${ }^{33}$. - Bien comido Capitán llévatelo luego toda la familia, te hemos escuchado, come nomás y llevate ${ }^{34}$.

- GROARRR.... NGUMMM..... NGUMMM.......

- ¡Capitán! ¡Sácamelo!, ¡Sácamelo! Olor... olor....olor...jsácamelo! $!^{35}$

- Capitán...jolor, olor, sácamelo siempre, Capitán! ${ }^{36}$. Mucho ha cargado olor porque siempre....jhasta el final no más es! ${ }^{37}$.

- ¡Gerardo! ¿Tienes miedo? ${ }^{38}$.

- ¡No tataaa! ${ }^{39}$

- ¡Estás temblando en ahí! ${ }^{40}$ Si tenemos miedo, un poquito a nosotros nos puede comer, también ${ }^{41}$.

- Este día que hemos entregado ahora él va a comer totalmente ${ }^{42}$. No tengáis miedo ${ }^{43}$ ¡hasta el final no más es! Ya han comido, han tragado, han arrojado aquí olor, a nosotros nos quiere aplastar como un pan, por eso más mejor nosotros entregamos no más ¡que esté corriendo su sangre! $!^{44}$.

Terminada la consulta y una vez estipuladas las ofrendas precisas que hay que realizar, las aphällas del ch'amakani se despiden de todos reafirmando que el problema ya ha sido resuelto, como podrán verificar los afectados a su retorno a los yungas. Todos los presentes damos las gracias y una vez concretadas las ofrendas a realizar, encendemos los mecheros de queroseno y con ellos vuelve la luz a la estancia cambiando notablemente nuestras sensaciones. Los objetos del ch'amakani, especialmente los ingredientes para hacer las ofrendas rituales y el tari $^{45}$ donde dispone las hojas de coca que hemos estado pijchando ${ }^{46}$ a lo largo de toda la sesión, aparecen revueltas y desordenadas como testimonio de que también "ellos", los seres tutelares, los aphällas que 
han intervenido en el ceremonial, han consumido su parte correspondiente.

La forma en que el maestro dramatiza en la sesión la muerte de los culpables, devorados ávidamente por el demonio, reproduce una forma de antropofagia ritual que se aplica a la ingesta de las entidades espirituales, "sombras", ch'iwis, de la víctima. La complejidad de la aflicción que afectaba a la familia precisaba de otras atenciones rituales complementarias.

El "maestro" preparó cuatro mesas ${ }^{47}$, dos ch'iyara misas $^{48}$, una para el demonio Capitán, otra para su mujer, Sirinu ${ }^{49}$, que tenían que ser entregadas en el cementerio de la comunidad en lugar de las víctimas ${ }^{50}$. Luego acondicionó una "mesa de salud" para proteger a la familia de los afectados y finalmente una mesa para pachamama y kunturmamani, por tratarse de los primeros días de agosto $^{51}$, para favorecer la venta y productividad del negocio familiar y sus terrenos de cultivo.

La imagen del demonio andino está presente, por tanto, en la etnografía andina contemporánea si bien no con los ribetes que el catolicismo pretendía inculcar mediante su imagen aterradora, como responsable de los pactos maléficos que los "hechiceros y ministros del diablo" de la Colonia, realizaban en su anhelo por chupar niños y devorarlos en sus juntas diabólicas, escenas propias de los aquelarres europeos (Fernández Juárez 2012). Sin embargo, los seres tutelares aymaras propios del manqhapacha (el mundo de abajo y de adentro), los del ámbito saxra (maligno) de la realidad, los ñanqhas, sirinus, tíos ${ }^{52}$, anchachus, antawallas, jajos, diablos, demonios, "satanás" 53 y demás parentela, comparten con el resto de los seres tutelares del Altiplano, los del alaxpacha (mundo de arriba) y también los del akhapacha (este mundo) un deseo irrefrenable por apropiarse de todo lo humano, empezando por su propio cuerpo; de hecho, las mesas rituales pretenden, en su variedad, atemperar ese voraz apetito de las entidades tutelares del Altiplano que cuando hambrean arrebatan las "sombras", ch'iwi, a los pobladores andinos para devorarlas, provocando de esta forma enfermedades y aflicciones que pueden concluir con la muerte del infortunado. Como vemos, en el caso descrito es el demonio quien devora a la víctima en sus entidades anímicas o espirituales; no es el ch'amakani, sino el demonio que ha incorporado en la sesión ceremonial. Si se le pregunta al ch'amakani después de la sesión suele hacerse el esquivo como si no recordara nada, de hecho ese "secreto de confesión" resulta clave para mantener la lealtad de sus clientes. El especialista ritual nunca reconocerá públicamente este tipo de habilidades, insistiendo en que la responsabilidad del maleficio realizado no es suya sino de quien le solicitó el "trabajo" y en última instancia del propio demonio convocado.

$\mathrm{Si}$ analizamos en clave comparativa las descripciones sobre los "come hombres" coloniales, frente a los que documenta la etnografía contemporánea, observamos la relevancia que los cronistas y los jesuitas otorgan a la demonología violenta destacando la efusión de sangre y actitudes vampíricas "por el sieso y la natura" en coherencia con idénticos referentes hispánicos en el ámbito de la brujería de la época o con prácticas de hechicería como el levantamiento de figura y la elaboración de tortas o masas en representación de la persona. De hecho, los propios cronistas hablan de devorar el alma de la víctima de esta forma. El demonio es el protagonista, quien dictamina entre sus seguidores las técnicas maléficas a realizar para acabar con las víctimas elegidas. Es el demonio el antagonista que ejerce su tutela sobre brujos y brujas, los considerados como "hechiceros y ministros del diablo", es decir, los especialistas en rituales andinos de la época. Por el contrario, frente a este modelo colonial, el ejemplo etnográfico contemporáneo que hemos presentado refleja el protagonismo nuclear del especialista ritual, en este caso del ch'amakani, que es quien convoca al demonio que es tratado como uno más de sus asesores ceremoniales, marcado por el signo andino de las predilecciones anímicas frente a las corporales de los cronistas. Este criterio que prioriza la protección o el acceso a las entidades anímicas que constituyen el ser humano en el Altiplano es coherente con los propios criterios médicos locales que reconocen el peor de los pronósticos con la captura y deglución del ajayu, la principal de las entidades anímicas de los pobladores aymaras en las comunidades ribereñas del lago Titicaca.

Agradecimientos: Quisiera reconocer a todas aquellas instituciones que apoyaron y propiciaron el trabajo de campo preciso para la realización del presente artículo: Universidad de Castilla-La Mancha (España); CSIC (España); AECID en La Paz (Bolivia); CIPCA, La Paz (Bolivia); ESA, La Paz (Bolivia). Igualmente a los evaluadores de este artículo que han contribuido en gran medida a mejorar su puesta final. 


\section{Referencias Citadas}

Absi, P. 2005. Los Ministros del Diablo. El Trabajo y sus Representaciones en las Minas de Potosí. IRD, IFEA, La Paz. Albornoz, C. de, 1990 [1577]. Información de Servicios (Cuzco 1577). En El Retorno de las Huacas, compilado por L. Millones, pp.167-201, Instituto de Estudios Peruanos y Sociedad Peruana de Psicoanálisis, Lima.

Álvarez, B.1998 [1588]. De las Costumbres y Conversión de los Indios del Perú. Memorial a Felipe II. Edición de María del Carmen Martín Rubio, Juan J.R. Villarías y Fermán del Pino Díaz. Polifemo, Madrid.

Ansión, J. 1987. Desde el Rincón de los Muertos. El Pensamiento Mítico en Ayacucho. Gredes, Lima.

Ansión, J. (ed.) 1989. Phistacos. De verdugos a Sacaojos. Tarea, Lima.

Arriaga, P.J. 1968 [1621]. La Extirpación de la Idolatría en el Pirú. BAE, Madrid.

Bastien, J.1986. Etnofisiología andina: evidencia lingüística, metafórica, etiológica y etnofarmacológica para conceptos andinos sobre el cuerpo. Arinsana 1:5-24.

Caro Baroja, J. 1975. Brujería Vasca. Txertoa, San Sebastián.

Cervantes, F. 1996. El Diablo en el Nuevo Mundo. El Impacto del Diabolismo a Través de la Colonización de Hispanoamérica. Herder, Barcelona.

Cañizares-Esguerra, J. 2008. Católicos y Puritanos en la Colonización de América. Marcial Pons, Madrid.

Cohn, N. 1997 [1976]. Los Demonios Familiares de Europa. Altaya, Barcelona.

Duviols, P. 1977. La Destrucción de las Religiones Andinas (Durante la Conquista y la Colonia). Universidad Autónoma de México, México.

Estenssoro, J.C. 2003. Del Paganismo a la Santidad. IFEA/ Pontificia Universidad Católica del Perú, Lima.

Federici, S. 2010. Calibán y la Bruja. Mujeres, Cuerpo y Acumulación Originaria. Traficantes de sueños, Madrid.

Fernández Juárez, G. 1995a. El Banquete Aymara: Mesas y Yatiris. HISBOL, La Paz.

Fernández Juárez, G. 1995b. Imágenes, intelecto, palabras: El ojo del sueño en la formación de un "maestro" ceremonial aymara. Revista Andina 26:389-420.

Fernández Juárez, G. 1997. Entre la Repugnancia y la Seducción. Ofrendas Complejas en los Andes del Sur. Centro de Estudios Regionales Andinos "Bartolomé de las Casas", Cusco.

Fernández Juárez, G. 1998. Iqiqu y Anchanchu: enanos, demonios y metales en el Altiplano aymara. Journal de la Société des Américanistes 84:147-166.

Fernández Juárez, G. 2000. El culto al "tío" en las minas bolivianas. Cuadernos Hispanoamericanos 597:25-31.

Fernández Juárez, G. 2004a. Ajayu, Animu, Kuraji. La enfermedad del "susto" en el altiplano de Bolivia. En Salud e Interculturalidad en América Latina. Perspectivas Antropológicas, coordinado por G. Fernández Juárez, pp. 279-304. Abya-Yala, Quito.
Fernández Juárez, G. 2004b. Yatiris y Ch'amakanis del Altiplano Aymara. Sueños, Testimonios y Prácticas Ceremoniales. AbyaYala, Quito.

Fernández Juárez, G. 2006. Kharisiris de agosto en el Altiplano aymara de Bolivia. Chungara Revista de Antropología Chilena 38:51-62.

Fernández Juárez, G. 2008. Kharisiris en Acción .Cuerpo, Persona y Modelos Médicos en el Altiplano de Bolivia. AbyaYala y CIPCA, Quito.

Fernández Juárez, G. 2010. Norte contra Sur. Análisis comparativo sobre ofrendas rituales andinas. Revista Española de Antropología Americana 40:239-259.

Fernández Juárez, G. 2011. Maleficios Corporales. Posesión, Hechicería y Chamanismo en España y América (Siglos XVIXXI). Abya-Yala, Quito.

Fernández Juárez, G. 2012. Hechiceros y Ministros del Diablo. Rituales, Prácticas Médicas y Patrimonio Inmaterial en los Andes (Siglos XVI-XXI). Abya-Yala, Quito.

Fernández Juárez, G. 2014. Un Zugarramurdi caribeño: las brujas de Tolú y Cartagena (1633). Revista Internacional de los Estudios Vascos 59:52-79.

Fernández Nieto, M. 1989. Proceso a la Brujería. En Torno al Auto de fe de los Brujos de Zugarramurdi. Logroño, 1610. Tecnos, Madrid.

Gil García, F.M. y G. Fernández Juárez 2008. Dossier. El culto a los cerros en el mundo andino: estudios de caso. Revista Española de Antropología Americana 38:105-113.

Girault, L. 1988 [1972]. Rituales en las Regiones Andinas de Bolivia y Perú. CERES/MUSEF/QUIPUS, La Paz.

Gutiérrez Estévez, M. 2010. Esos cuerpos, esas almas. Una introducción. En Retóricas del Cuerpo Amerindio, editado por M. Gutiérrez y P. Pitarch, pp. 9-55. Iberoamericana, Madrid.

Henningsen, G. 1983. El Abogado de las Brujas. Brujería Vasca e Inquisición Española. Alianza Editorial, Madrid.

Idoate, F. 1972. Un Documento de la Inquisición Sobre Brujería en Navarra. Aranzadi, Pamplona.

Marcos Casquero, M.A. y H.B. Riesco Álvarez 1997. Pedro de Valencia. Obras Completas, VII. Discurso Acerca de los Cuentos de las Brujas. Universidad de León, León.

Martínez, G. 1998. Sobre Brujos y Lik'ichiris. La Creación Cultural del Horror. Ministerio de Justicia y Derechos Humanos, Banco Mundial, La Paz.

Molina, C. de, 2008 [1575]. Relación de las Fábulas y Ritos de los Incas. Edición, Estudios y Notas por Julio Calvo Pérez y Henrique Urbano. Universidad de San Martín de Porres, Lima.

Molinié, A.1991. Sebo bueno, indio muerto: la estructura de una creencia andina. Boletín del Instituto Francés de Estudios Andinos 20:79-92.

Monast, J.E. 1972. Los Indios Aimaraes: ¿Evangelizados o Solamente Bautizados? Lohle, Buenos Aires.

Morote, E. 1988 [1952]. El Nakaq. En Aldeas Sumergidas. Cultura Popular y Sociedad en los Andes, editado por E. Morote, pp. 153-177. Centro de Estudios Regionales Andinos "Bartolomé de las Casas", Cusco. 
Nash, J.1985. Religión, rebelión y conciencia de clase en las comunidades mineras, Allpanchis Phuturinqa 26:115-135.

Neila Boyer, I. 2006. El samay, el susto y el concepto de persona en Ayacucho (Perú). En Salud e Interculturalidad en América Latina. Antropología de la Salud y Crítica Intercultural, coordinado por G. Fernández Juárez, pp. 187-215. Abya-Yala /UCLM, Quito.

Platt, T.1988. Religión andina y conciencia proletaria. Fe y Pueblo 13:31-35.

Polia, M. 1989. Contagio y pérdida de la sombra en la teoría y práctica del curanderismo andino del Perú Septentrional: Provincias de Ayabaca y Huancabamba. Anthropologica 7:195231.

Polia, M. 1999. La Cosmovisión Religiosa Andina en los Documentos Inéditos del Archivo Romano de la Compañía de Jesús, 1581-1752. Pontificia Universidad Católica del Perú, Lima.

Ramalle, E. y M. Azurmendi (eds.) 2010. Inquisición y Brujería. El Auto de Fe de Logroño de 1610. Instituto de Estudios Riojanos, Logroño.

Rivière, G. 1991. Lik'ichiri y kharisiri. A propósito de las representaciones del "otro" en la sociedad aymara. Bulletin de l'Institut Française d'Etudes Andines 20:23-40.

Rösing, I. 2008a. Defensa y Perdición: La Curación Negra. Rituales Nocturnos de Curación en los Andes Bolivianos. Iberoamericana/Vervuert, Madrid.

Rösing, I. 2008b. Cerrar el Círculo: La Curación Gris como Tránsito Entre la Negra y la Blanca. Rituales Nocturnos de Curación en los Andes bolivianos. Iberoamericana/Vervuert, Madrid.

Sánchez, J. 2007. La imposición del diabolismo cristiano en América. Cuadernos del Minotauro 5:23-47.

Saignes, T. (comp.) 1988. Borrachera y Memoria. La Experiencia de lo Sagrado en los Andes. Hisbol, La Paz.
Saignes, T. 1989. Borracheras andinas: ¿Por qué los indios ebrios hablan en español? Revista Andina 7:83-127.

Sharon, D. 1980. El Chamán de los Cuatro Vientos. Siglo XXI, México.

Spedding, A. 2005. Sueños, Kharisiris y Curanderos. Editorial Mama Huaco, La Paz.

Splendiani, A.M. 1997. Cincuenta Años de Inquisición en el Tribunal de Cartagena de Indias 1610-1660, cuatro volúmenes. Pontificia Universidad Javeriana, Santa Fe de Bogotá.

Tausiet, M. 2008. Por el sieso y la natura. Una lectura literaria de los procesos por brujería. Edad de Oro XXVII:339-364.

Taylor, G. 1980. Supay. Amerindia 5:47-63.

Tedlock, B. 1995. La cultura del sueño en las Américas. En De Palabra y Obra en el Nuevo Mundo, 4. Tramas de la Identidad, editado por J. Klor, pp.127-169. Junta de Extremadura/Siglo XXI. Madrid.

Urbano, H. 2011. Pablo Joseph de Arriaga. SJ. Retórica y extirpación de idolatrías en el Arzobispado de Lima, siglos XVI - XVII. En Religión y Heterodoxias en el Mundo Hispánico, siglos XIV-XVIII, editado por R. Izquierdo y F. Martínez, pp. 153-169. Sílex, Madrid.

Usunáriz, J.M. (ed.) 2012. Akelarre: La Caza de Brujas en el Pirineo (Siglos XIX-XIX). Eusko Ikaskuntza, San Sebastián.

Zamora Calvo, M.J. 2008. Las bocas del diablo. Tratados demonológicos en los siglos XVI y XVII. Edad de Oro XXVII:411-445.

\section{Notas}

1 En la celebración de los 400 años de aquel hecho lamentable que dio en la hoguera con 11 encausados, cinco en efigie y seis en persona, merece la pena destacar las publicaciones que al albor del homenaje a aquellas víctimas inocentes han permitido actualizar los datos sobre el caso. Merece la pena resaltar el monográfico de la Revista Internacional de Estudios Vascos, coordinado por Jesús María Usunáriz (2012) y el volumen publicado por el Instituto de Estudios Riojanos y el Ayuntamiento de Logroño, editado por Enrique Ramallo y Mikel Azurmendi (eds) (2010).

2 Si bien existen montañas en la tradición vasco-navarra que son consideradas lugares específicos de reunión de brujas, en el caso de los Andes, las "plazuelas de los cerros" adquieren una nueva relevancia y dimensión cultural como escenario propicio para el desarrollo de prácticas rituales y ceremoniales (Gil García y Fernández Juárez 2008).

3 Empleando la retórica y el ejemplo a modo de relato convincente, el "demonio-huaca" se revela enemigo acérrimo de los españoles, los defensores del evangelio. El discurso semeja en parte las revelaciones y denuncias de los taquioncoys tal y como acredita la crónica de Molina [1575] y las informaciones de Cristóbal de Albornoz [1577]. Los "brujos", en masculino, hechiceros y dogmatizadores del relato del jesuita, se emparentan con las "brujas", en femenino, herejes del célebre proceso de Zugarramurdi en las montañas navarras que culminó en el conocido auto de fe de Logroño en noviembre de 1610. Sobre las peculiaridades del caso de Zugarramurdi ver (Caro Baroja 1975:71-147; Marcos Casquero y Riesco Álvarez 1997; Fernández Nieto 1989; Henningsen 1983). El hecho de que los indígenas hablen el español y el contexto ritual específico del que se trata coincide con lo que la etnografía contemporánea nos indica en los casos de hebriedad. Ese "estar en otra cabeza" del indígena borracho en plena celebración le exime incluso de responsabilidades penales (Saignes 1988:43, 1989). Para analizar con más profundidad los usos sociales y rituales del consumo de alcohol en los Andes (ver Saignes 1988).

4 Las brujas, en el dominio peninsular español, eran consideradas expertas "chupadoras" de niños pequeños, de los que se decía que les chupaban la sangre y sus esencias vitales por el sieso (el ano), la vagina, o incluso estrujándoles las sienes (Tausiet 2008:343).

5 Episodios que son prestados del modelo de aquelarre peninsular, destacando por su importancia y relieve el "modelo de Zugarramurdi" exportado en su versión más crédula a tierras americanas, como podemos apreciar en el Auto de Fe de 1633 en Cartagena de Indias, que afectó a brujas, mulatas y negras criollas de las localidades de Tolú y Cartagena (Splendiani 1997; Fernández Juárez 2014). Gracias al trabajo etnográfico de Ina Rösing (2008a; 2008b), conocemos de forma detallada las prácticas maléficas que en torno a las mesas negras, yana mesas, desarrollan los 
indígenas kallawayas del Norte del departamento de La Paz en la actualidad, con el deseo expreso de acabar con la vida de la víctima. Para ello emplean ingredientes y sustancias como sapos y escarabajos atravesados con espinas; grasa de cerdo y de oveja; excrementos de burro; cuernos izquierdos de carnero o toro; levantamiento de figuras y reproducciones en alambre con ropas y cabellos de la víctima,... etc., todo ello aderezado con las prédicas adecuadas donde se reitera el deseo de la muerte del difunto y el acompañamiento de oraciones como el Padre Nuestro. Los preparados ceremoniales suelen enterrarse en el cementerio o según los casos en las inmediaciones donde vive la persona a la que se desea dañar. Para una perspectiva comparada sobre maleficios ibéricos y amerindios ver Fernández Juárez 2011.

6 Las comidas nefandas de los aquelarres ibéricos producen el mismo efecto (Idoate 1972:135).

7 En la Carta Аnnua de 1617 de la Misión a los indios del Corregimiento de La Barranca y Cajatambo encontramos datos muy similares a los anteriormente descritos por el jesuita Luis Teruel (Polia 1999).

8 La literatura etnográfica sobre la figura del kharisiri aymara o sus contrapartes quechuas como son, el pihstaku y el ñak'aq, resulta abundante (Molinié 1991; Rivière 1991; Morote 1988 [1952]; Ansión 1987; Ansión Edit. 1989; Martínez 1998; Spedding 2005; Fernández Juárez 2006,2008).

9 Estos expertos en ritual fueron sometidos al proceso de diabolización que justificaba en sus hábitos y prácticas ceremoniales la persistencia presencia e influjo del demonio según los criterios de los cronistas y eruditos de los siglos XVI y XVII, como podemos apreciar en los procesos de extirpación de idolatrías (Cervantes 1996; Fernández Juárez 2012; Sánchez 2007; Urbano 2011).

10 Ch'amakani. Especialista ritual de especial relevancia y prestigio en el Altiplano aymara. Su virtud principal es la capacidad que presenta para hablar y conversar con las entidades tutelares de los Andes en sesiones nocturnas, que se efectúan en completa oscuridad, ch'amaka, posibilitando el desdoblamiento del especialista en varios personajes con voces propias que interpelan a lo largo de la sesión ceremonial, tanto al propio especialista como al resto de participantes. Cada ch'amakani tiene sus propios colaboradores ceremoniales que son quienes intervienen en la sesión con sus voces, a reclamo del especialista. Según el talante del propio ch'amakani, estos seres que intervienen en las consultas y que responden al propio proceso de iniciación del especialista en ritual, pueden ser los cerros achachilas, los rayos o bien santos del catolicismo. En el caso que vamos a analizar, los aphällas del ch'amakani serán San Jerónimo, voz grave y carácter desagradable, San Felipe, voz atiplada y socializador, San España, voz suave, encargado de llevar de un extremo a otro del Altiplano, las encomiendas y mandatos que resulten pertinentes en el desarrollo de la sesión ceremonial (Fernández Juárez 2004b).

11 Valles cálidos próximos a la ciudad de La Paz, conocidos por su producción de hojas de coca para el consumo tradicional de las comunidades aymaras del Altiplano.

12 Los sueños, en las culturas andinas, son considerados como indicadores de cuestiones relativas a la vida inminente del soñador. Son considerados auguradores de situaciones que advierten al soñador según el modelo de sueño y su persistencia recurrente (Fernández Juárez 1995b; Tedlock 1995).
13 Los pobladores aymaras consideran que cada persona posee, al menos, tres entidades anímicas denominadas, en el ámbito lacustre del Titicaca, como ajayu, ánimo y coraje. Estas tres entidades sufren de episodios de fuga ante cualquier imprevisto, que los separa del cuerpo, siendo causa de diversas enfermedades e incluso pudiendo provocar la muerte, en los casos extremos en los que son capturadas por los seres tutelares del Altiplano y devoradas por ellos. Estas entidades anímicas son conocidas con el genérico de ch'iwi en aymara, es decir, "sombra", como también se las denomina en el norte del Perú (Fernández Juárez 2004b; Polia 1989). La pérdida de una de estas $c h$ 'iwis implica la consulta al especialista ritual de turno para su pronta restitución, en previsión de que el caso se agrave si no se resuelve con eficacia. La consideración de las entidades anímicas en el sector kallawaya del norte del departamento de La Paz es similar a la cuenca del Titicaca, como recoge Bastien: "El ánimo se llama juchuyajayu ( ајауи pequeño), y el alma se llama jatunajayu (ajayu grande). Cuando una persona pierde su juch'uyajayu, él no muere, pero enferma, se desorganiza y su cuerpo empieza a secarse (la sangre se vuelve delgada, la piel empalidece, se manifiesta una extenuación general). Cuando una persona pierde su jatunajayu, la persona muere porque su cuerpo se seca" (Bastien 1986:13, 14). Para una introducción general sobre la significación antropológica de las entidades anímicas y su relevancia en el concepto de "ser humano" en las culturas amerindias, Gutiérrez Estévez (2010:9-55).

14 Es una práctica habitual en la restitución de las entidades anímicas extraviadas o en la simple consulta médica, según la perspectiva de la medicina aymara, emplear las ropas de la persona afectada o sobre la que se desea averiguar algo, en caso de que no pueda desplazarse en persona a la casa del yatiri o ch'amakani. Recuerdo la expresión empleada por el ch'amakani al indicarle este hecho de la ropa: "son como sus pelos". Recordemos que también la ropa es empleada en los dominios de la hechicería americana y peninsular desde tiempos añejos, en especial las enaguas y los calzones (Fernández Juárez 2011).

15 El conflicto se ve recrudecido o exponencialmente amplificado por el efecto de resonancia que produce en la comunidad el hecho de que sean "compadres" entre sí.

16 Así como se entiende que la hoja de coca forma parte del patrimonio cultural inmaterial de los pueblos andinos, no sucede lo mismo con la "cocaína", considerada por los propios aymaras como un "asunto de gringos" y fervientemente rechazada por las comunidades más tradicionales que achacan a los que practican el pisado de coca o la elaboración de cocaína actitudes insolidarias con la propia comunidad. El enriquecimiento rápido que supone el comercio de cocaína o su dedicación al pisado de coca en los campamentos clandestinos los emparenta con el kharisiri y sus procedimientos nocivos de extracción de grasa y sangre al que se atribuye su poder de destrucción. En el 2009 se rumoreaba en ciertos sectores de La Paz el descubrimiento, en algunas comunidades cercanas, de pequeños laboratorios de producción de cocaína, lo que indicaría, de ser cierto, nuevas formas de convivencia con el narcotráfico por parte de las comunidades aymaras.

17 Cada uno de los sospechosos de infligir daño a la familia de los presentes en la sesión fue convocado mediante su 
ajayu por parte del especialista, incorporando sus voces, sometiéndolas a un tremendo interrogatorio y finalmente castigándolas sonoramente como si fueran efectivamente golpeadas por las entidades tutelares que el ch'amakani había convocado en la sesión.

18 Aphällas: así denomina el ch'amakani a sus apoyos ceremoniales quienes le colaboran en su sesión chamánica; también los denomina "asentaron".

19 El demonio se presenta ante todos los presentes. Lógicamente solo escuchamos su voz y la sensación de que toquetea y enreda con las cosas que el propio especialista estaba preparando, antes de soplar los mecheros de queroseno que nos alumbraban.

20 Es el "capitán" de los demonios, es decir, el de mayor graduación e importancia, el "principal", de igual manera que hemos visto en los relatos coloniales. La tradición demonológica y erudita europea establecía esta diferencia en la relevancia e importancia de los diferentes demonios personificados de forma individualizada con nombres específicos cuyo prestigio radicaba, entre otras cosas, en el número de legiones que comandaban (Zamora Calvo 2008).

21 Obviamente, "nos quieren matar". El especialista ritual pone al demonio en antecedentes sobre el caso y, además, se incluye mayestáticamente entre los afectados.

22 Es una lucha de depredadores rituales. La familia rival quiere acabar con la vida de los afectados, " se los quieren comer" por los encargos maléficos efectuados por ellos y que ya acabaron con la vida del padre.

23 Una vez planteado el problema es responsabilidad del demonio el adoptar la forma específica en que se materialice la venganza concreta sobre los agresores: "cualquier cosa les va a pasar".

24 El demonio rápidamente acepta la versión de los afectados y emplea toda su agresividad en el tratamiento de violencia simbólica que aplicará a los infractores. El demonio gruñe enfurecido.

25 He cambiado la identificación de los implicados a posta. He optado por darles un apellido aymara de lo más común como es Mamani.

26 Es importante la adecuada identificación de las personas a las que se desea victimar para que el maleficio que se formula expresamente tenga éxito.

27 El demonio avisa a los aphallas del Ch'amakani que va a empezar a devorar a las víctimas.

28 El que habla es el aphalla principal, San Jerónimo, animando al demonio para que acabe con rapidez con el ajayu de los agresores. La ingesta que hace el demonio, a pesar de todas las degluciones sonoras, que hace mediante el ch'amakani, como si efectivamente estuviera devorando algo orgánico, afecta a las entidades anímicas de sus víctimas, a sus ch'iwis, en especial al ajayu, el principal, cuyo extravío y deglución por cualquier entidad tutelar del Altiplano se considera causa de muerte.

29 Manq'ata: come.

30 Hasta el final, es decir, hasta su muerte.

31 Anima al demonio en su labor depredadora San Felipe, otro de los aphallas del Ch'amakani. Choca en este caso la actuación de esta entidad que suele ser pacífica y conciliadora en las labores habituales del especialista ritual.

32 Engulle el demonio con voracidad.
33 Dice el demonio con una voz profunda; hasta el final, es decir, hasta la muerte. Comienzan a escucharse gritos de dolor del propio ch'amakani.

34 Dice San Jerónimo. "Llévate", como se indica en las comidas colectivas aymaras a los invitados. En los japt'api, cada comensal y muy especialmente si hay invitados por alguna circunstancia excepcional deben llevarse hasta la última migaja de comida en una bolsa o similar. Dejar algún rastro de comida, por parte de los invitados, supone una profunda descortesía en las comunidades aymaras.

35 San Jerónimo urge al demonio a que saque de la habitación los despojos de la víctima porque están impregnando la sala de un aroma nauseabundo a podrido, testimonio del efecto logrado por parte del demonio al devorar las entidades anímicas de los dañados. El olor a podrido atestigua la muerte de las víctimas. Desconozco el producto que el ch'amakani emplea para provocar ese efecto odorífico.

36 Ruega en esta ocasión San Felipe; el diablo accede y se va, llevándose con él su festín; es decir, los restos mortales de las víctimas expresados mediante sus entidades anímicas devoradas.

37 Hasta su muerte, comenta San Jerónimo.

38 Me interpela San Jerónimo, una vez que el demonio ha partido.

39 Consigo articular en un hilo de voz apenas audible, todavía bajo los efectos de la sorpresa inesperada del drama que el especialista ritual había escenificado en la obscuridad en su versión demoníaca; la voracidad del demonio expresada en aquel sinnúmero de sonoras degluciones nauseabundas, estuvo a punto de hacerme evacuar el estómago en varias ocasiones.

40 Me recrimina con crudeza San Jerónimo.

41 El temor, el miedo, la timidez, son circunstancias que permiten el extravío o el secuestro de las ch'iwi provocando la aflicción y la enfermedad en su propietario. La más extendida de dichas dolencias es el "susto", si bien matizando su gravedad en función de la entidad ceremonial andina que haya provocado su extravío y captura (Fernández Juárez 2004a; Neila Boyer 2006).

42 El demonio.

43 San Jerónimo se dirige a los presentes antes de despedirse.

44 Como vemos el aphälla del ch'amakani establece una relación directa entre los acontecimientos sufridos por las entidades anímicas y el cuerpo físico de la víctima, es decir, entre su sangre y sus "sombras" (ch'iwi).

45 Tari, objeto textil cuadrangular en el que se portan las hojas de coca en las comunidades aymaras próximas al lago Titicaca.

46 Pijchar, se refiere al acto social característico de buena parte de las sociedades andinas, consistente en mascar las hojas de coca.

47 Mesa: ofrenda ritual compleja elaborada con una pluralidad de ingredientes ceremoniales. Su tipología es diversa en función del dominio cultural (aymara, quechua, uruchipaya, kallawaya) al que nos refiramos, e incluso dentro del mismo grupo étnico y lingüístico podemos apreciar matices y diferencias sustanciales. Su uso ceremonial se encuentra muy extendido por todos los Andes del Centro y Sur, contrastando significativamente con las "mesadas" de la costa norte del Perú (Fernández Juárez 1995, 1997, 2010; Girault 1988; Sharon 1980). 
Ch'íyara misas. "Mesas negras" de especial relevancia en los procesos de brujería y devolución ceremonial del daño (Rösing 2008a).

49 Sirinu. Entidad vinculada en el Altiplano con los afloramientos de agua.

50 Este procedimiento consiste en enterrar los objetos ceremoniales que han sido preparados para hacer daño, de forma que se concrete en su última instancia la muerte de los enemigos mediante el entierro en el cementerio de aquellos objetos rituales que los representan. En ocasiones los procedimientos de recuperación terapéutica de ciertas dolencias establecen una dinámica semejante en la que se entierran en el cementerio los objetos o restos orgánicos (perros desollados, cuys, gallos... etc.) que han representado en el ritual al enfermo con el ánimo de "engañar" a la enfermedad. Al hacer la transferencia del cuerpo del enfermo al cuerpo del animal específico desollado y al enterrar dicho animal en nombre del enfermo, como si este hubiera muerto, la enfermedad es "engañada" y abandona el cuerpo del doliente.

51 Agosto es el mes ritual por excelencia en el Altiplano aymara. La madre tierra, pachamama, hambrea, "tiene la boca abierta" y recibe complacida las ofrendas rituales que constituyen su alimentación. A cambio facilita protección en la casa, kunturmamni, y fecundidad en los campos de cultivo.

52 El término "tío" se aplica a una de las entidades del dominio minero que mejor encajan con el concepto de "diablo", al menos en su aspecto externo. El "tío" es el dueño del mineral y hace cambiar la fecundidad de las vetas a su antojo. Cada "socavón" minero potosino presenta su propia estatuilla del "tío", a la que los mineros homenajean martes y viernes, con libaciones de alcohol y pijchu de coca, con especial énfasis en período de Carnaval (Absi 2005; Fernández Juárez 2000; Nash 1985; Platt 1988).

53 Todos ellos son términos que identifican a los seres del manqhapacha aymara. Algunos como los términos "demonio", "diablo" e incluso "satanás" que emplean algunos ch'amakanis de la zona del lago Titicaca son de indudable origen europeo aunque presenten aditamentos andinos peculiares, como hemos apreciado en el relato del “demonio capitán”. El conocido término quechua zupay, supay, supaya empleado por los cronistas para denominar al demonio adolece, desde sus inicios, de problemas de interpretación por su vinculación con el ámbito de los difuntos como muestra el padre Álvarez en el remoto Altiplano orureño de finales del siglo XVI: “ [ [....]Y así, en todas las maneras que les hablaba o [se] les aparecía, le llamaban el çupai; y a ninguna cosa de cuantas tratan no tienen en uso llamar çupai sino a los muertos que están en las sepulturas [...] Todo este cuento bien he entendido, y dél-entendiendo que en este nombre, çupai, sólo entienden los muertos- se podrá considerar si es error el que se les enseña cuando les dicen "çupayo diablo sutini" [ = "el çupai se llama diablo]. En uno son dos errores: el uno es que les dan a entender que el muerto es demonio; por donde, sabiendo -como por su ciencia saben- que el çupai fue persona, decirles nosotros que el çupai se llama diablo no es otra cosa sino darles a entender que en nuestro vocablo llamamos diablo al hombre muerto; y esto es error" (Álvarez 1998 [1588]:155-156). Sobre el debate histórico, antropológico y linguiístico en torno al concepto "Zupay" ver Estenssoro 2003; Taylor 1980; Urbano 2011. 
